\title{
Bioethics in Denmark
}

\section{moving from first-to second-order analysis?}

Nielsen, Morten Ebbe Juul; Andersen, Martin Marchman

Published in:

Cambridge Quarterly of Healthcare Ethics

DOI:

10.1017/S0963180113000935

Publication date:

2014

Document version

Early version, also known as pre-print

Citation for published version (APA):

Nielsen, M. E. J., \& Andersen, M. M. (2014). Bioethics in Denmark: moving from first-to second-order analysis?

Cambridge Quarterly of Healthcare Ethics, 23(3), 326-333. https://doi.org/10.1017/S0963180113000935 


\title{
Bioethics in Denmark
}

\author{
Moving from First- to Second-Order Analysis?
}

MORTEN EBBE JUUL NIELSEN and MARTIN MARCHMAN ANDERSEN

\begin{abstract}
This article examines two current debates in Denmark-assisted suicide and the prioritization of health resources-and proposes that such controversial bioethical issues call for distinct philosophical analyses: first-order examinations, or an applied philosophy approach, and second-order examinations, what might be called a political philosophical approach. The authors argue that although first-order examination plays an important role in teasing out different moral points of view, in contemporary democratic societies, few, if any, bioethical questions can be resolved satisfactorily by means of first-order analyses alone, and that bioethics needs to engage more closely with second-order enquiries and the question of legitimacy in general.
\end{abstract}

Keywords: assisted suicide; prioritization; health resources; philosophical analysis

\section{Overview}

Viewed through the lens of public opinion, Denmark counts as a liberal or permissive country concerning key areas of bioethics, such as abortion and assisted reproduction; as a moderately liberal one with regard to support for stem cell research; ${ }^{1}$ and, perhaps surprisingly, as a moderately bioconservative one in matters of food resources, genetically modified organisms, and so on. ${ }^{2}$ Moreover, there is a very high level of public support for the country's policy of free and equal access to the vast majority of health services, primarily excluding dental services for adults and most forms of cosmetic surgery, and including some level of user payment for most drugs.

\section{Two Current Debates in Denmark: Voluntary Euthanasia and the Prioritization of Health Resources}

In general, on broadly bioethical issues there is a high level of agreement and accordance between voters and political parties, whether or not they are in government. However, there is a notable gap between the public's attitude and that of members of parliament as concerns one question: namely, voluntary euthanasia (including assisted suicide). A survey finds that 71 percent of the public is in favor of legalizing voluntary euthanasia and assisted suicide, whereas only 20 percent of members of parliament (MPs) are in favor of doing so. ${ }^{3}$ Traditionally, MPs are to vote according to their own conscience on matters of morality (in reality: bioethical questions) and not according to their party line; moreover, there is no discernible right-left distribution of MPs supporting or opposing legalization. In this chapter, we offer some reflections on this discrepancy, which is atypical of the Danish political practice.

As mentioned, free and equal access to healthcare enjoys widespread support both in the public and among MPs. Surveys show that the topic of health consistently 


\section{Bioethics in Denmark}

figures among the top three political priorities of the Danes, and, not to put too fine a point on it, arguing for cuts in the health budget is tantamount to political suicide. Nevertheless, questions about prioritization in health, especially in conjunction with worries over an aging population and the ongoing economic crisis, are more and more pressing. There seems to be a growing recognition of the fact that healthcare resources are finite; that the possibilities for appropriating a larger proportion of public finances for health purposes are limited, given competing demands for other public services; and finally that the demand for health services is ever growing. However, few, if any, politicians, academics, nongovernmental organizations (NGOs), or other civil society organizations have attempted-or risked - to be clearer about which values and principles should inform prioritization. This has spurred the quango (quasi-autonomous regulatory agency) Danish Council of Ethics (discussed subsequently) to try to place the question of prioritization on the agenda of public debate. We offer here some (rather abstract) reflections on why it is so difficult to openly debate issues of prioritization of healthcare resources in the context of a broadly egalitarian society, and some tentative suggestions as to how bioethicists could contribute to progress in this difficult debate.

\section{Two Levels of Analysis}

Controversial bioethical issues, such as voluntary euthanasia and the prioritization of healthcare resources, call for two distinct philosophical analyses: first-order examination of the cases in the light of various established moral theories (the applied philosophy or first-order approach) and second-order enquiries into the question of legitimacy in the light of reasonable pluralism (what might be called a political philosophical or simply a second-order approach). We believe that in contemporary democratic societies, few, if any, bioethical questions can be resolved (politically) satisfactorily by means of first-order analyses alone. Citizens cannot be expected to converge seamlessly toward one first-order morality that can underpin policies on most bioethical issues. This situation calls for second-order analyses: in the light of the pluralism of first-order moral views, which policies can form the basis for a reasonable, overlapping consensus? We shall argue that first-order examination is indeed important to tease out the implications of various moral points of view vis-à-vis concrete, bioethical questions, but that bioethics needs to engage more closely with second-order enquiries and the question of legitimacy in general. Denmark might be an interesting case for such analyses.

\section{Academic and Institutional Structures}

There are no large, designated centers of bioethical research in the country; however, there is a vibrant tradition of doing applied ethics at both philosophy departments and various health, public health, or bioscience institutions. From both a public debate and a policy point of view, however, the most important institution is the quango Danish Council of Ethics. ${ }^{4}$ Following an arm's-length principle, the council gives advice to the government and endeavors to spur public debate on biotechnological and more broadly health-related ethical questions. The council was created in 1987 by the government in the wake of controversies over in vitro fertilization and similar biotechnological breakthroughs. In its now more than 25 years of existence, only very few of its members have been academic 


\section{Morten Ebbe Juul Nielsen and Martin Marchman Andersen}

philosophers. Members are appointed by a government committee and by the ministers of the relevant areas (health, environment, etc.). The council is often seen as more conservative than the population on key issues such as assisted suicide or new technologies, and it attracts a good deal of media attention. This might be due to the (perhaps ironic) common confusion about the role and powers of the council, which, apart from stimulating discussion, are only to give advice and make reports to parliament, not to legislate or perform any adjudicative role. Often, the council is seen as an official state branch issuing ethical verdicts on deeply controversial issues-or perhaps the media spins their stories in a way that fits with such an interpretation.

\section{Case 1: Prioritization of Healthcare Resources}

Seen in a global light, Denmark is a highly egalitarian nation: its GINI coefficient, measuring the inequality among levels of income, wavers around 0.24 , putting the country among the top three most egalitarian as concerns economic resources, ${ }^{5}$ and marginal tax rates are between 48.5 and 69.1 percent, according to which method is being used. ${ }^{6}$ Free and equal access to a range of health services is seen as one of the cornerstones of the social model. Private hospitals, which are financed mostly by private insurance and public sector out-contracting, have been accepted as an add-on to the model. However, private sector hospitals account for only a fraction of resources spent, that is, approximately less than 3 percent.

It is on this highly egalitarian background that one should read the controversy over prioritizing health resources. Of course, equality per se is only half the story: it is easy to achieve equality if one simply lowers the quality of services to a minimum. What welfare-state-supporting Danes expect is, of course, not only equal but also high-quality services, and hence the controversy. There is an ingrained discomfort to the idea that health services cannot be "the best" across the board, and perhaps an even greater dislike of the idea that some should receive the best while others cannot. Moreover, the background is not only egalitarian but also, to a high degree, one of consensus and cooperation. While acknowledging differences of both objective and ideological interests among citizens, the Danish model (and history) of democracy has traditionally emphasized a consensual rather than a conflict or agonistic model of political life.

It is hard to paint a cogent picture of how prioritization is being handled in the Danish healthcare sector. There is no equivalent to the United Kingdom's National Institute for Health and Care Excellence (NICE), ${ }^{7}$ and there is no official policy reflecting one or the other principle of prioritization. The overall health budget is, of course, a matter for parliament, but regional administrative bodies can prioritize to some extent within the budget, and a certain amount of on-the-ground (in the clinic, hospital, etc.) prioritization is bound to take place as well.

Discomfort about the necessity of facing challenges of prioritization is not sufficient to quell the discussion. One sign that this is so is that the Danish Council of Ethics has issued a report concerning prioritization. ${ }^{8}$ The contributors, who include a broad range of politicians, medical experts, public health administrators, philosophers, representatives of NGOs, and so on, advocate no unified take on the question of prioritization. In fact, they hardly advance any concrete, philosophically informed views on prioritization at all. Although their publication-if it is indeed a precursor to an open debate on prioritization—can, and should, be 


\section{Bioethics in Denmark}

viewed as an important stepping stone, it is also perhaps typical of the uncertainty and general feeling of unease as concerns taking a definite stand on the issue of prioritization.

We submit that bioethics needs to concern itself less with first-order moral analysis and more with second-order political philosophy approaches, specifically theories of distributive justice and public reason in the light of (reasonable) pluralism-or at least that bioethicists need to inform themselves more about such theories. Of course, prioritization is from the beginning a distributive question, so we might be pushing at an open door. In any event, the issue of prioritization is not one that is solved by applying some first-order moral theory (or distributive principle, for that matter). For any principle of prioritization there is bound to be important and reasonable objections, hence the need to move from first-order principles that aim at being true to second-order principles that aim at being reasonable, or, as far as possible, legitimate. The move from first-order ethical thought to second-order discussions of legitimacy will almost always imply dispensing with the notion of an ideal solution-the kind of solution that various theoretical, ethical points of view aim to provide. Given reasonable pluralism, the ideal is not the ideal, if you allow the play on words. Rather, "in an account of real public reason, the aim of moral theory is not to paint pictures of an ideal world but to show how we can achieve a real social morality that meets the test of moral acceptability of the real reason of moral agents."

It might sound as if the peculiarly egalitarian and consensus-seeking background on which the Danish debate of prioritization is to take place would make such a move easier. However, we speculate that, precisely due to that background, the debate and the move might become harder. The Danish welfare state is by and large the product of a series of compromises in which a predominantly moderate socialdemocratic majority of working- and middle-class citizens and associations gradually has moved the distributive profile toward more equality in key areas such as income and education. However, it is probably easier to compromise in areas such as minimum wages than it is on the prioritization of healthcare resources, in which access to a given procedure or drug is, or is seen as being, an all-or-nothing issue. As concerns a broad range of social issues-unemployment benefits, public student funding, paid holidays, public pensions, and so on-compromises are relatively easy to achieve because even small increments are benefits, and because trade-offs between various benefits and burdens offer themselves more readily to the involved parties. However, prioritization of scarce health resources will inevitably mean that someone-the elderly, the ones with rare or expensive or "unsexy" diseaseswill lose. Therefore trade-offs are much harder to imagine. The egalitarian Danish consensus model is, in spirit at least, built on the principle that no one should be left (completely) behind. But all plausible forms of prioritization, given moderate scarcity of resources and unlimited demand, will imply that some are left behind-at least relatively speaking. Hence, a compromise on the principle(s) to be used to guide prioritization is not easily forthcoming. On the other hand, not prioritizing - that is, not having official and transparent principles of prioritizing-does not mean that the problem of scarce resources and unlimited demand disappears: prioritizing will simply take place in forms and ways that are more or less invisible to the public.

Such distributive problems are, of course, the bread and butter of political theorists and philosophers. That is not to say that political philosophy provides a panacea 


\section{Morten Ebbe Juul Nielsen and Martin Marchman Andersen}

to the problem of legitimacy given pluralism and reasonable disagreement-far from it. However, we submit that bioethics could benefit from engaging more closely with political philosophy in the endeavor to find legitimate models of prioritization, and that the Danish case might be very interesting to follow in this regard.

\section{Case 2: Voluntary (Active) Euthanasia or Assisted Suicide}

Passive euthanasia, or withholding medical treatment, is not illegal and is accepted in Denmark. However, voluntary (active) euthanasia, when a doctor or some other person actively ends the life of a consenting patient, or helps a patient to take his or her own life, is illegal. As already mentioned, there is a stark contrast between the citizenry and the politicians in this regard: 71 percent of the public is in favor of legalizing voluntary euthanasia and assisted suicide, whereas only 20 percent of MPs are in favor of doing so.

The Danish Council of Ethics takes a conservative approach similar to that of the members of parliament, though with some minority dissent. ${ }^{10}$ As is usual for the council, there are no final recommendations, executive summaries, or other statements of the council's conclusions. However, a massive majority (15 out of 17) recommends that there should be no changes to the laws regarding euthanasia. Two members recommend further investigation into the likely consequences of allowing voluntary euthanasia, and the same two members recommend that we should consider allowing assisted suicide. ${ }^{11}$ The council seems to put great emphasis on the availability of palliative medicine as an alternative that, barring some fringe cases, renders euthanasia obsolete. ${ }^{12}$ Against this, it could reasonably be argued that the council does not adequately address the plight of those patients who do not want hospice or palliative care to begin with; fear of pain is not the only reason why some persons want to control their own end of life.

In any event, the schism between parliament (and the council) and the population is tangible. Naturally, many explanations of this discrepancy are available: Perhaps politicians lack the courage to face up to their responsibility to follow the democratic majority because they fear that they will not win any new votes but lose some of their existing ones. Maybe citizens are not informed enough about palliative care or have not thought through the implications of legislation. Perhaps ethical councils have a tendency to recruit, or produce, ethical absolutists. Rather than spending more time speculating about the causes of the discrepancy, we move forward by raising the same point as we did earlier in relation to the question about prioritization. We also go a bit further toward proposing some ways ahead that are hopefully illustrative.

When two citizens, A and B, stand opposed on the question of voluntary euthanasia, it seems like compromise, in a strict sense, is impossible: either voluntary euthanasia is legal (given a string of further qualifications and conditions, of course) or it is illegal. ${ }^{13}$ This is unfortunate if one allows for the possibility that neither citizen is unreasonable in holding his or her point of view, because whether or not the state legalizes voluntary euthanasia, the (ex hypothesi reasonable, or at least not unreasonable) point of view of one of the citizens is not accommodated, and hence he or she is not treated with due respect, given liberal premises. Moreover, because the pluralism in question is reasonable, then, in practice, no amount of first-order discussion about and clarification of the morality of 


\section{Bioethics in Denmark}

euthanasia and related concepts will guarantee consensus, hence the need to move to second-order discussions of legitimacy.

Legitimacy is, of course, not a neutral concept. It is nevertheless fair to say that liberal political philosophy (from Rawls and onward) is by far the school of thought that has paid the most attention to the specific problem involved, namely, legitimacy given reasonable pluralism and given the reasonability of the involved parties. Like legitimacy, reasonability is not an uncontroversial concept, but most seem to accept that reasonability is not (primarily, at least) connected with the content of doctrines and ideals held by any given agent. Rather, the concept refers to a way of holding or having a doctrine or ideal. To elaborate, we need here briefly to introduce a distinction between two ways of being opposed to some policy, act, or practice. Suppose citizen $C$ is opposed to homosexuality. $C$ can then be opposed to homosexuality in two very different ways. A liberal-compatible and reasonable way of being so inclined means, roughly, that $C$ does not support homosexuality (this might include things such as not wanting to be around homosexuals, refusing to watch movies that depict homosexuality, campaigning against homosexuality, and many other things conventionally deemed intolerant or illiberal), but that $\mathrm{C}$ nevertheless supports laws that allow homosexuals to engage in their practices and that refrain from interfering actively with their rights to do so. A liberal-incompatible and unreasonable way of being opposed to homosexuality entails precisely a denial of the last part of this definition. Note that reasonability does not entail giving up one's personal preferences and ideals, nor does it require any kind of positive attitude toward specific acts or preferences. It also does not necessarily require any kind of close scrutiny and assessment of the values and principles underlying such acts. Moreover, reasonability entails a readiness to accept principles regulating the affairs of all, given reciprocal respect for the same principles by other parties.

Approaching the question of voluntary euthanasia in the light of reasonability invites the following line of thought: clearly, it is unreasonable for anyone to demand of another person that he or she should volunteer for euthanasia. But conversely, it seems unreasonable for an opponent of voluntary euthanasia to demand of another person that he or she should refrain from undergoing euthanasia. ${ }^{14}$ The upshot is that we should let voluntary euthanasia be an individual decision, but with strong emphasis on protection of those who manifestly are opposed to becoming subjects of euthanasia. Evidently, individuals can and will be affected by collective decisions (or their absence). If it is plausible that legalizing voluntary euthanasia leads to, for example, preemptive killing of the elderly to "prevent suffering," then individuals opposed to euthanasia are indeed not unreasonable if they demand that euthanasia should remain unlawful. However, this and similar slippery-slope-style arguments seem not to be well founded in empirical research. ${ }^{15}$ In any event, strong emphasis on institutional safeguards against misuse is well justified independently of fear of various slippery slopes.

We are of course aware that many argumentative steps need to be filled in for the conclusion to be logically compelling, but note that it is reached without much inquiry into first-order questions about the moral acceptability of euthanasia: it follows from admitting reasonable disagreement or pluralism concerning some question, and from a spirit of wanting to find mutually justifiable and binding principles in the light of such disagreement. From this it might be taken that we would argue for the redundancy of first-order analyses. This is not our view: 


\section{Morten Ebbe Juul Nielsen and Martin Marchman Andersen}

careful scrutiny of real bioethical problems in the light of various cogent moral theories is not rendered obsolete. In order to establish the possible grounds for compromise and accommodation of various (reasonable) points of view, firstorder analyses will play a crucial role. In other words, there is plenty of room for "classic" bioethical inquiry.

\section{Concluding Remarks: Bioethical Enquiry at a Crossroads?}

We have focused on two current bioethical issues that are pressing in a Danish context. One is the question of assisted suicide/voluntary euthanasia, where there is a marked difference between voters and politicians regarding whether or not it should be legalized. We have offered a model, inspired by recent turns in liberal political philosophy, that might not be ideal but nonetheless seems better equipped to deal with the question of legitimacy, given reasonable pluralism, than any model built solely on first-order moral enquiry. The other issue concerns the prioritization of healthcare resources, a discussion that in the peculiarly egalitarian Danish setting generates so much unease that it is very difficult to move ahead. However, because prioritization is a necessity, avoiding open, yet potentially painful, deliberation seems unreasonable. Because prioritization is first and foremost a distributive problem, bioethics needs to connect with contemporary discussions in political philosophy.

Classical bioethical first-order analyses are important. They tease out the implications of considered ethical points of view. Often they show implications that we do not expect to see, or at the very least they clarify how and why one might arrive at a given conclusion. From the point of view of reaching legitimate decisions that minimize forms of democratic discontent, close analysis of various considered views, their foundations, and their implications is a crucial step. However, combining this form of analysis with second-order analyses of the grounds for compromise and reasonable accommodation of pluralism provides the most directly relevant form of study of bioethical questions.

\section{Notes}

1. Blendon RJ, Kim MK, Benson JM. The public, political parties, and stem-cell research. New England Journal of Medicine 2011;365:1853-6.

2. Eurobarometer. Social values, science and technology [special report]; 2005. http://www.freeenterprises.co.uk/Religion-Statistics / Eurobarometer/Social-Values-Science-Technology.pdf (last accessed 18 March 2014).

3. Schelde N, Vaaben L. Helt uenige om aktiv dødshjælp: Folket er for, politikerne imod. http:// www.etik.dk/artikel/509067:Aktiv-doedshjaelp--Helt-uenige-om-aktiv-doedshjaelp--Folket-erfor--politikerne-imod (last accessed 13 May 2013).

4. For a short introduction, see the council's Web site, available at http:/ / www.etiskraad.dk/da-DK. aspx?sc_lang=en (last accessed 13 May 2013).

5. See, e.g., Global Gini index (Distribution of family income) ranking by country. http://www. mongabay.com/reference/stats/rankings/2172.html (last accessed 15 May 2013).

6. These figures are based on the 2013 data from the Danish tax ministry.

7. There is an advisory board concerning expensive in-hospital drugs, Rådet for Anvendelse af Dyr Sygehusmedicin, but the function of this board is, as implied by the name, mainly consultative.

8. Danish Council of Ethics. Ethics and prioritization in the health sector: Why is it so difficult?; available at www.etiskraad.dk/ /media/bibliotek/misc/2013/Etik-og-prioritering-i-sundhedsvaesenethvorfor-det-er-saa-svaert.pdf (last accessed 16 May 2013).

9. Gaus G. The Order of Public Reason. Cambridge: Cambridge University Press; 2011, at 446. 


\section{Bioethics in Denmark}

10. See Danish Council of Ethics. Det Etiske Råds Udtalelse om eventuel lovliggørelse af aktive dødshjælp; available at http://www.etiskraad.dk/Hoeringssvar/2012/18-09-2012-udtalelse-om-eventuellovliggoerelse-af-aktiv-doedshjaelp.aspx?sc_lang=da-DK (last accessed 18 march 2013).

11. See note 10, Danish Council of Ethics, at 8ff.

12. See note 10, Danish Council of Ethics, at 16-18.

13. Nothing important follows from whether we take voluntary euthanasia or assisted suicide as an example, or so we believe.

14. This seems unreasonable at least given some standard qualifications and conditions. It is not necessarily unreasonable to expect a person with a perfectly good life, several years of expectedly good quality ahead, and good mental and physical health not to end her own life, or so we would argue.

15. See, e.g., Rietjens JAC, van der Maas PJ, Onwuteaka-Philipsen BD, van Delden JJM, van der Heide A. Two decades of research on euthanasia from the Netherlands: What have we learnt and what questions remain? Bioethical Inquiry 2009;6:271-83. doi:10.1007/s11673-009-9172-3. 